
\title{
Synthesis and Magnetic Properties of Mn- Zn Ferrite Obtained by Decomposition of Precursor by Sunlight
}

\author{
Vikas J. Pissurlekar \\ Department of Chemistry, P.E.S."s S.R.S.N College of Arts and Science, Ponda, Goa. - 403401
}

\begin{abstract}
Magnetic nano-materials are extensively studied because of their wide range of applications. The Mn-Zn ferrite is amongst the most important magnetic materials and has attracted a great interest in technology because of its use in memory or data storage devices, magnetic recording heads, switches and other electromagnetic gadgets. Low temperature single phase nano crystalline Mn $n_{x}$ n ${ }_{(1-x)} \mathrm{Fe}_{2} \mathrm{O}_{4}(x=0.4,0.5$ and 0.6) were prepared by decomposition of precursor by sunlight. Stoichiometric amounts of manganese oxide, zinc oxide and ferric oxide are taken as starting materials. Mixture of these oxides were homogenized by using ball-mill and then treated with a ligand to produce a precursor. The samples obtained after the decomposition of precursor were characterized by infrared spectral analysis (IR), X-ray diffraction (XRD) and atomic absorption spectroscopy (AAS). The lattice parameters increase with increase in Mn content (8.4386-8.4552 $\mathrm{A}^{\mathrm{o}}$ ). The particle size, determined by Scherer formula, is found to be in nano range between $17 \mathrm{~nm}$ to $26 \mathrm{~nm}$. The saturation magnetization values are in the range $22.47 \mathrm{emu} / \mathrm{g}-41.63 \mathrm{emu} / \mathrm{g}$ and hysteresis loss is found to be low for all the samples. The Curie temperature ( $\mathrm{Tc})$ is in the range $473 \mathrm{~K}-558 \mathrm{~K}$.
\end{abstract}

Keywords: Nano material; Magnetic properties; Oxides; Sunlight; self-decomposition

\section{Introduction}

Magnetic iron oxide nanoparticles are of high interest due to their unique properties. Among them $\mathrm{Mn}-\mathrm{Zn}$ ferrites are one of the most widely used magnetic materials due to their low hysteresis loss and high saturation magnetization The applications of these versatile magnetic material ranges from actuators, electromagnetic gadgets, switches, sensors, transformers etc. [1] to biomedical applications [2]-[3]. Even though, it has many applications in various fields as bulk material [4] as well as their new applications as nanoparticles [5], an increase in the demand for the development of new synthesis routes for $\mathrm{Mn}-\mathrm{Zn}$ ferrite nano particles, still exists and are explored by different group of researchers. Therefore, the improvement and understanding of various new synthesis routes that allow the achievement of highly crystalline materials is a constant need. As reported in the literature by different researchers [6]-[7]. It is very important to have the accurate control of chemical composition and particle size distribution for the preparation of high quality $\mathrm{Mn}-\mathrm{Zn}$ ferrite powders. The most common method of producing $\mathrm{Mn}-\mathrm{Zn}$ ferrite powders in the large amount in industry is via the traditional ceramic technology, involving solid phase reactions at high temperatures, of mixture of oxides [8]-[9], which is often faced with difficulties of providing high quality powders required for the high performance devices because of the poor phase and compositional control, in homogeneities in compound, as well as of larger and wider particle size distributions and impurities. Many novel and innovative wet-chemical methods are tried successfully in recent years to prepare high quality ultrafine powders or nanopowders, including the co-precipitation [10]-[11], hydrothermal process [12][13], sol-gel [14]-[15] and sol-gel auto-combustion [16][17]. In this study a novel method was tried in which solid oxides of manganese, zinc and iron were ball milled to obtain a homogenous mixture which was then treated with a ligand hydrazinium acetate to obtain a precursor which was exposed to sunlight and on drying undergoes auto combustion- self decomposition- to give ultrafine $\mathrm{Mn}-\mathrm{Zn}$ ferrite.

\section{Experimental}

The stoichiometric amounts of pure $99.9 \%$ manganese dioxide (Sigma-Aldrich make), zinc oxide (Thomas Baker make) and ferric oxide (Thomas Baker make) was taken as starting materials. The mixture was then ball-milled with ball to material ratio of 10 at $80 \mathrm{rpm}$ speed for $10 \mathrm{hrs}$ in Acmas Technocracy Ball Mill (model Acm - 8203) to obtain a powdered mixture. This mixture was then treated with calculated amount of aqueous hydrazinium acetate and homogenized to a thick paste. The resulting paste containing mixed metal oxides was exposed to sunlight as shown in the figure 1 it dried slowly by the sun rays. It was observed that, on drying the paste swells and undergoes auto combustionself decomposition- to finely divided solid powder which was found to be magnetic in nature. The procedure was repeated for other samples and, the final product, in each case, was used for characterization as well as to study the structural, magnetic and electrical properties.

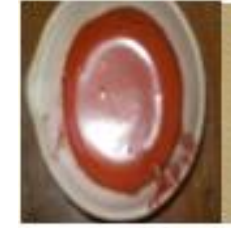

(a)

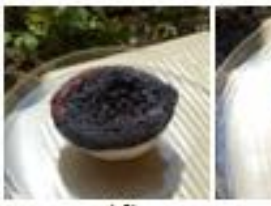

(d)

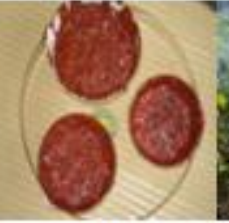

(b)

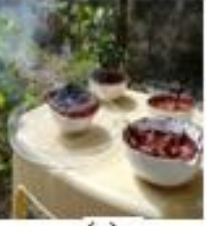

(c)

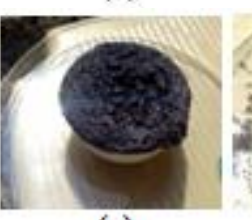

(e)

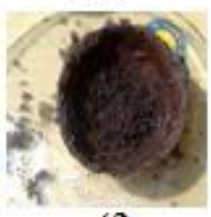

(f)
Figure 1 (a) to (f): Photos showing different stages of Photo-catalytic auto combustion self- decomposition of a precursor 


\section{International Journal of Science and Research (IJSR) \\ ISSN (Online): 2319-7064}

Index Copernicus Value (2013): 6.14 | Impact Factor (2014): 5.611

The IR spectra of Mn-Zn ferrite samples were recorded by using FTIR Shimadzu Model IR prestige 21 series spectrophotometer. In a typical experiment, the solid ferrite sample was finely ground along with the pure and dry $\mathrm{KBr}$, in the ratio $1: 10$. Fine grinding is required for the sample to be uniformally mixed with $\mathrm{KBr}$. The mixture was then put in a sample holder and placed in the sample chamber of the IR spectrophotometer. The absorption spectrum for the sample was recorded in the wavelength range $1000 \mathrm{~cm}^{-1}$ to $400 \mathrm{~cm}^{-1}$. Atomic absorption spectroscopy is a method for elemental analysis. It is also useful in detecting, both qualitatively and quantitatively, the trace metals and it is independent of the molecular form of the metal in the sample. The method is highly sensitive and can detect different metals in concentration of less than one ppm.

The structural characterization of the prepared Mn-Zn ferrite nanopowders was carried out using Rigaku, X-ray advance Power diffractometer using $\mathrm{Cu} \mathrm{K} \alpha$ radiation $(\lambda=1 \cdot 54183$ $\AA)$. The step size employed was $0 \cdot 02^{\circ}$, in the range of $20^{\circ}-$ $80^{\circ}$. The average particle size $\mathrm{T}$ was calculated using most intense peak (311) employing the Scherer formula. The particle size and morphology was carried out using Scanning Electron Microscope Model JEOL 5800LV.

The saturation magnetization measurements of all the samples were carried out at room temperature using Pulse Field Magnetic Hysteresis Loop Tracer, supplied by Magneta India Model PFMHT-1. Magnetization,coercivity and remanent magnetization were calculated from the hysteresis loops. The Curie temperature of all the Mn-Zn ferrite samples was determined. The measurements were done by using Dual Channel Data Acquisition System supplied by Magneta India Model pfm-2.

\section{Results and Discussion}

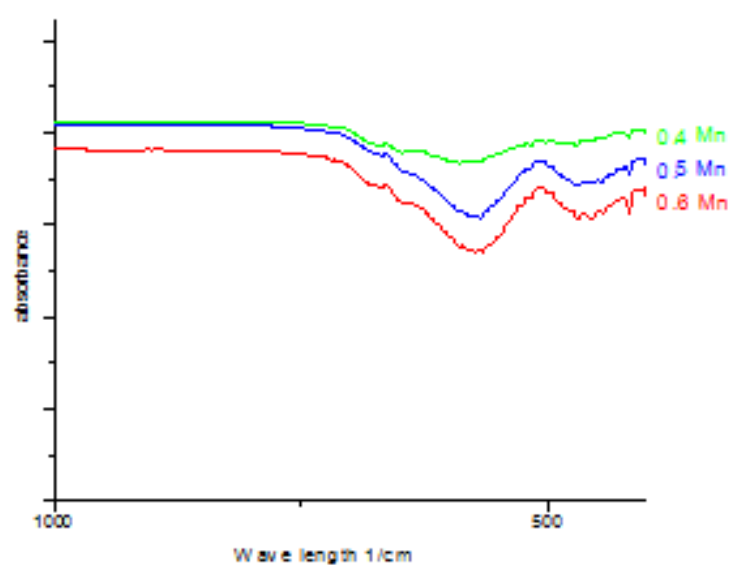

Figure 2: IR Spectra of $\mathrm{Mn}_{\mathrm{x}} \mathrm{Zn}_{(1-\mathrm{x})} \mathrm{Fe}_{2} \mathrm{O}_{4}$

The infrared spectra of all the ferrite samples are shown in the Figure 2 recorded in the range of $1000-400 \mathrm{~cm}^{-1}$.

Infrared spectra of various ferrites have been studied by Waldron [18], reporting two bands in the region $1000 \mathrm{~cm}^{-1}$ to $200 \mathrm{~cm}^{-1}$. He attributed the high frequency $\left(v_{1}\right)$ band to tetrahedral metal-oxygen bond and second frequency $\left(v_{2}\right)$ band to octahedral metal-oxygen bond corresponding to:

(a) $\mathrm{Me}_{\mathrm{T}}-\mathrm{O}-\mathrm{Me}_{\mathrm{O}}$ stretching vibration $600-550 \mathrm{~cm}^{-1}$

(b) $\mathrm{Me}_{\mathrm{O}} \mathrm{O} \longleftrightarrow$ stretching vibration $450-385 \mathrm{~cm}^{-1}$

here $\mathrm{O}$ is oxygen, $\mathrm{Me}_{\mathrm{O}}$ is metal in the octahedral site and $\mathrm{Me}_{\mathrm{T}}$ in the tetrahedral site. The metal-oxygen absorption bands (a) and (b) are pronounced for all spinel structures and essentially for ferrites, which are also seen in these samples. IR spectral data of all the ferrite samples prepared by these methods are found to show two peaks in the range 588-569 $\mathrm{cm}^{-1}$ and $462-447 \mathrm{~cm}^{-1}$ which are in agreement with the reported value [19]-[20].

$\mathrm{Mn}-\mathrm{Zn}$ ferrite powder samples of different compositions of $\mathrm{Mn}$ and $\mathrm{Zn}$ were accurately weighed and dissolved in minimum quantity of AR grade concentrated hydrochloric acid and the solution was diluted to ppm level by taking care that each powder sample has concentration of Fe ions in the range of 2 to $9 \mathrm{ppm}, \mathrm{Mn}$ ions in the range of 1 to $36 \mathrm{ppm}$ and $\mathrm{Zn}$ ions in the range of 0.4 to $1.5 \mathrm{ppm}$, as per the requirement of the AAS spectrophotometer of GBC Model 932AA.

Table 1: AAS, analysis data for ferrite samples

\begin{tabular}{|c|c|c|c|c|c|c|}
\hline \multirow{2}{*}{ Composition } & \multicolumn{2}{|c|}{ Mn content } & \multicolumn{2}{c|}{ Zn content } & \multicolumn{2}{c|}{ Fe content } \\
\cline { 2 - 7 } & Theol. \% & Exptl. \% & Theol. \% & Exptl. \% & Theol. \% & Exptl. \% \\
\hline $\mathrm{Mn}_{0.4} \mathrm{Zn}_{0.6} \mathrm{Fe}_{2} \mathrm{O}_{4}$ & 9.27 & 9.78 & 16.56 & 16.18 & 47.15 & 47.46 \\
\hline $\mathrm{Mn}_{0.5} \mathrm{Zn}_{0.5} \mathrm{Fe}_{2} \mathrm{O}_{4}$ & 11.65 & 11.82 & 13.86 & 13.39 & 47.36 & 47.59 \\
\hline $\mathrm{Mn}_{0.6} \mathrm{Zn}_{0.4} \mathrm{Fe}_{2} \mathrm{O}_{4}$ & 14.04 & 14.37 & 11.14 & 11.25 & 47.57 & 46.43 \\
\hline
\end{tabular}

The results obtained for $\mathrm{Fe}, \mathrm{Mn}$ and $\mathrm{Zn}$ ions in each sample are given in the Table 1 and the same are in agreement with the assigned stoichiometric compositions for the ferrite samples within the permissible experimental error. 


\section{International Journal of Science and Research (IJSR) \\ ISSN (Online): 2319-7064}

Index Copernicus Value (2013): 6.14 | Impact Factor (2014): 5.611

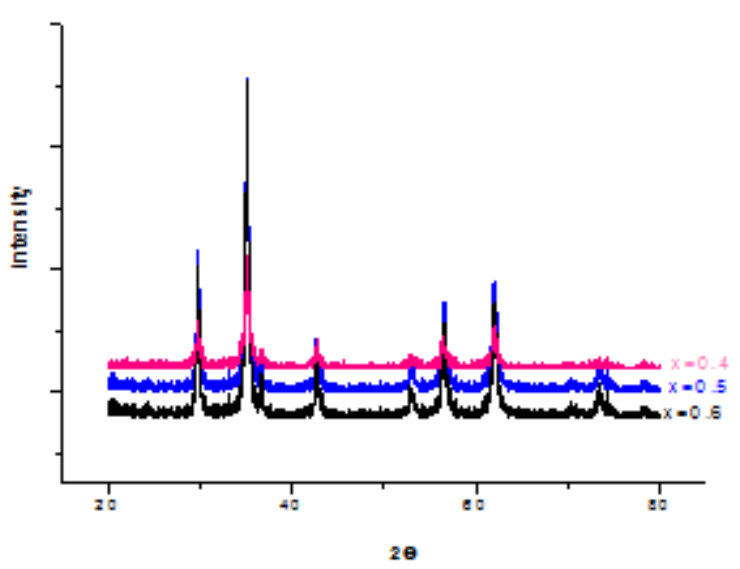

Figure 3: X-ray diffraction patterns of samples $\mathrm{Mn}_{\mathrm{x}} \mathrm{Zn}_{1-\mathrm{x}}$ $\mathrm{Fe}_{2} \mathrm{O}_{4}$,

Figure 3 shows the X-ray diffraction patterns of samples $\mathrm{Mn}_{\mathrm{x}} \mathrm{Zn}_{1-\mathrm{x}} \mathrm{Fe}_{2} \mathrm{O}_{4}$, where $\mathrm{x}=0.4$, 0.5, and 0.6 nanoparticles. All the peaks correspond to cubic spinel ferrite structure for all the samples and confirm the formation of single phase ferrite.

The values of lattice constants, ,ae calculated by using Scherer formula from the X-ray diffraction data for samples prepared by these were found to be in good agreement with the reported values [21]-[22].

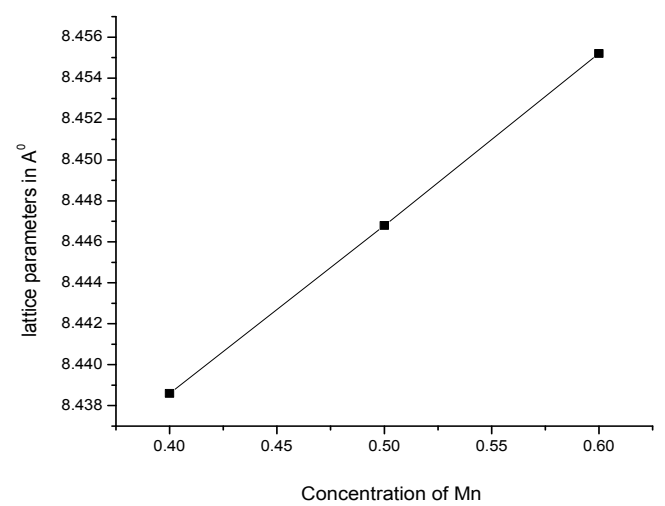

Figure 4: Variation of lattice parameters of samples $\mathrm{Mn}_{\mathrm{x}} \mathrm{Zn}_{1-\mathrm{x}} \mathrm{Fe}_{2} \mathrm{O}_{4}$,

Fig. 4 shows the variation of lattice parameter , $\mathrm{a}^{\text {ee }}$ as function of Mn concentration obtained by refining of XRD data. The lattice parameter increases linearly with increasing $\mathrm{Mn}$ content. For example, the lattice constant $8.4386 \AA$ for $\mathrm{Mn}_{0.4} \mathrm{Zn}_{0.6} \mathrm{Fe}_{2} \mathrm{O}_{4}$ increases gradually to $8.4552 \AA$ for $\mathrm{Mn}_{0.6} \mathrm{Zn}_{0.4} \mathrm{Fe}_{2} \mathrm{O}_{4}$. This increase could be attributed to the size of the ionic radii of $\mathrm{Mn}^{2+}$ and $\mathrm{Zn}^{2+}$ cations. As the concentration of $\mathrm{Mn}^{2+}$ increases, bigger $\mathrm{Mn}^{2+}$ cations $(0.91 \AA)$, replace smaller $\mathrm{Zn}^{2+}$ cations $(0.82 \AA)$ in the samples. Usually, in a solid solution within the miscibility limit of cubic phases a linear increment in the lattice parameter with concentration of cations is observed [23]-[24].

Average crystallite sizes were calculated by using XRD data by measuring the full-width at half maximum (FWHM) for most intense characteristic (311) peak for each sample with the help of the Scherer formula as given in equation 1, and are in the range 16-26 $\mathrm{nm}$ for different $\mathrm{Mn}$ concentrations.

Where, $\mathrm{T}$ is the average crystallite size, $\lambda$ is the $\mathrm{X}$-ray wavelength, $D_{p}$ the angular line width of half maximum intensity and $\theta$ is the Bragg angle in degrees. The particle size of $\mathrm{Mn}_{\mathrm{x}} \mathrm{Zn}_{1-\mathrm{x}} \quad \mathrm{Fe}_{2} \mathrm{O}_{4}$, where $\mathrm{x}=0.4, \quad 0.5$ and 0.6 nanoparticles with $\mathrm{Mn}$ concentration is given in table 2 .

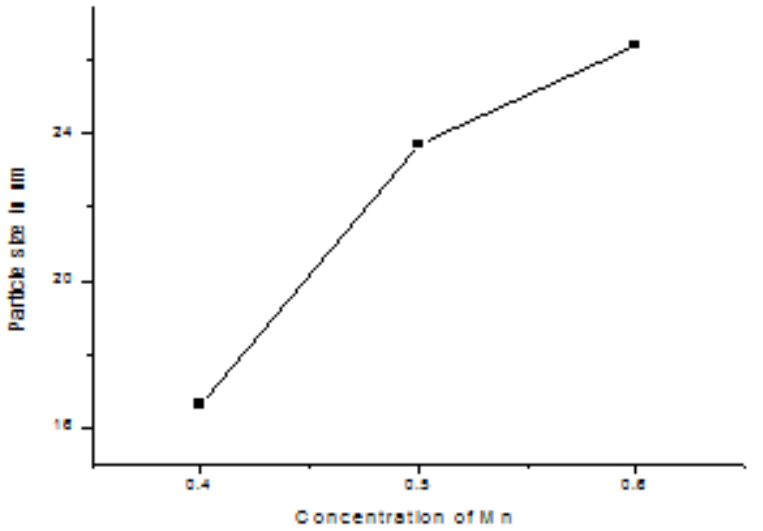

Figure 5: Variation of particle size with Mn content

Table 2: Variation of particle size

\begin{tabular}{|c|c|}
\hline Composition & Particle size in nm \\
\hline $\mathrm{Mn}_{0.4} \mathrm{Zn}_{0.6} \mathrm{Fe}_{2} \mathrm{O}_{4}$ & 16.7 \\
\hline $\mathrm{Mn}_{0.5} \mathrm{Zn}_{0.5} \mathrm{Fe}_{2} \mathrm{O}_{4}$ & 23.6 \\
\hline $\mathrm{Mn}_{0.6} \mathrm{Zn}_{0.4} \mathrm{Fe}_{2} \mathrm{O}_{4}$ & 26.4 \\
\hline
\end{tabular}

The crystallite sizes are found to increase with Mn content and in the range 16- $26 \mathrm{~nm}$ for different compositions. It is observed that crystallite size of $16 \mathrm{~nm}$ is observed for the ferrite sample with $\mathrm{Mn}$ concentration of $\mathrm{x}=0.4$ which increases to 26 for $\mathrm{Mn}$ concentration of $\mathrm{x}=0.6$ it may be due to the larger size of ionic radius of $\mathrm{Mn}^{2+}$ ions as shown in fig. 5 .

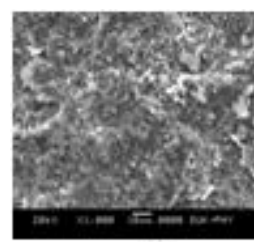

(a)

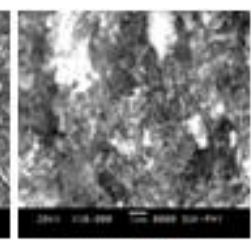

(b)

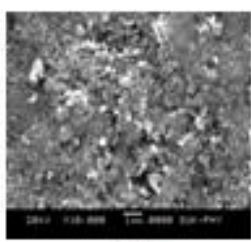

(c)

Figure 6: Shows SEM images of $\mathrm{Mn}_{\mathrm{x}} \mathrm{Zn}_{(1-\mathrm{x})} \mathrm{Fe}_{2} \mathrm{O}_{4}(x=0.4$, 0.5 and 0.6$)$ nanoparticles.

The morphology of $\mathrm{Mn}_{\mathrm{x}} \mathrm{Zn}_{1-\mathrm{x}} \mathrm{Fe}_{2} \mathrm{O}_{4}$, where $\mathrm{x}=0.4,0.5$, and 0.6 nanoparticles is shown in SEM micrographs in Fig. 6 (a), (b) and (c). For all compositions the Mn-Zn ferrites show similar morphology of particles. As seen in Fig. 6 particles show very strong agglomeration due to magnetic characteristic of particles and are of uniform grain size.

Table 3: Saturation Magnetization values of $\mathrm{Mn}-\mathrm{Zn}$ ferrite

\begin{tabular}{|c|c|}
\hline Concentration & Saturation Magnetization (emu/g) \\
\hline $\mathrm{Mn}_{0.4} \mathrm{Zn}_{0.6} \mathrm{Fe}_{2} \mathrm{O}_{4}$ & 22.47 \\
\hline $\mathrm{Mn}_{0.5} \mathrm{Zn}_{0.5} \mathrm{Fe}_{2} \mathrm{O}_{4}$ & 33.69 \\
\hline $\mathrm{Mn}_{0.6} \mathrm{Zn}_{0.4} \mathrm{Fe}_{2} \mathrm{O}_{4}$ & 41.63 \\
\hline
\end{tabular}

The saturation magnetization values, listed in Table 3, were measured at room temperature by determining hysteresis

\section{Volume 4 Issue 11, November 2015}




\section{International Journal of Science and Research (IJSR) \\ ISSN (Online): 2319-7064}

Index Copernicus Value (2013): 6.14 | Impact Factor (2014): 5.611

loops with a maximum applied magnetic field of $5 \mathrm{kOe}$. The saturation magnetization of $\mathrm{Mn}-\mathrm{Zn}$ ferrite nano particles increased continuously with an increase in Mn concentration for $0.4,0.5$ and 0.6 , from $22.47 \mathrm{emu} / \mathrm{g}$ for the $\mathrm{Mn}_{0.4} \mathrm{Zn}_{0.6} \mathrm{Fe}_{2} \mathrm{O}_{4}$ particles to $41.63 \mathrm{emu} / \mathrm{g}$ for $\mathrm{Mn}_{0.6} \mathrm{Mn}_{0.4} \mathrm{Fe}_{2} \mathrm{O}_{4}$ particles. The changes in magnetic properties are due to the influence of cationic stoichiometry and their occupancy in the specific sites, in addition to the formation of dead layers on the surfaces, existence of random canting of particle surface spins, non-saturation effects due to a random distribution of particle size and deviations from the normal cation distribution [25]. Moreover, it is known that $\mathrm{Mn}$ is unlikely at octahedral sites even at very fine crystalline sizes for ferrites with $\mathrm{x} \geq 0.6$. Consequently, no $\mathrm{Fe}^{3+}-\mathrm{O}-\mathrm{Fe}^{3+}$ magnetic interaction is possible in the $\mathrm{Mn}-\mathrm{Zn}$ ferrites. On the other hand, a part of total $\mathrm{Mn}^{2+}$ may occupy octahedral sites with $\mathrm{x}<0.6$ [26][27], therefore, it is not surprising that Mn-rich ferrites yield high values of saturation magnetization. All the samples show low values of coercivity indicating soft nature of the ferrites.

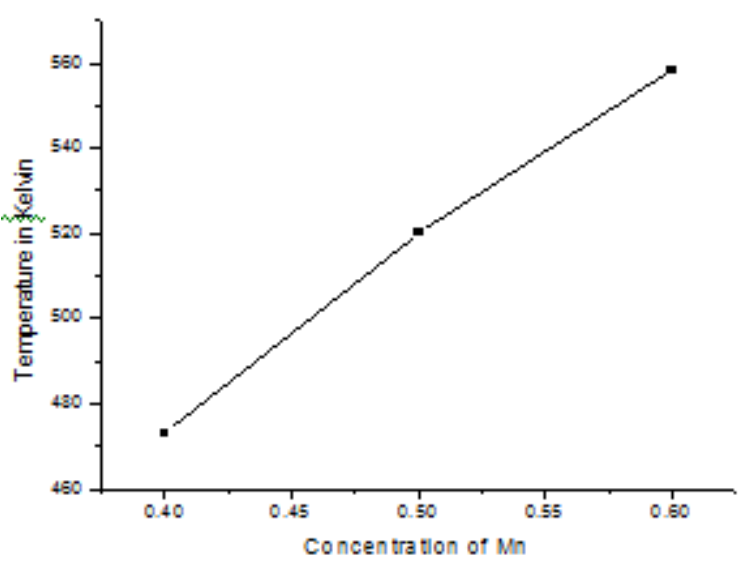

Figure 7: variation Curie temperature with Mn content.

The variation of the Curie temperature with increasing Mn content in Mn-Zn ferrite prepared by mechano-chemical method is given in Table 4, for prepared samples. It can be seen that, there was a systematic increase in the value of the Curie temperature $\left(\mathrm{T}_{\mathrm{c}}\right)$ from $473 \mathrm{~K}$ for $\mathrm{Mn}_{0.4} \mathrm{Zn}_{0.6} \mathrm{Fe}_{2} \mathrm{O}_{4}$ to $558 \mathrm{~K}$ for $\mathrm{Mn}_{0.6} \mathrm{Zn}_{0.4} \mathrm{Fe}_{2} \mathrm{O}_{4}$ as the manganese amount increases in these ferrites [20]. This is due to the substitution of non-magnetic $\mathrm{Zn}^{2+}$ ions by the magnetic $\mathrm{Mn}^{2+}$ ions in the samples. The value of $T_{c}$ is found to be higher in the case of the ultrafine powder than that in bulk ferrites. This is due to the deviation of cation distribution in a nano-sized particle as in comparison with its bulk counterparts [28]. In general, magnetic properties are controlled by exchange interaction of the metallic ions on the two interactive sub-lattices A and $B$. The change in $T_{C}$ may be positive or negative depending on the boundaries, the geometry, and the interaction. It is also possible that $T_{c}$ decreases due to some unknown surface effect. For small particles a significant fraction of atoms are on the surface, and it is reasonable to expect their magnetic interactions to be different. As such, a different average Curie temperature [29] is observed.

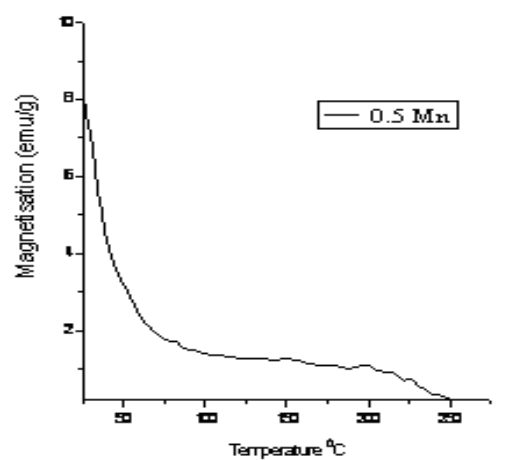

Figure 8: Graph of Curie temperature for $\mathrm{Mn}_{0.5} \mathrm{Zn}_{0.5} \mathrm{Fe}_{2} \mathrm{O}_{4}$

The nature of the $\mathrm{M}_{\mathrm{S}}$ versus $\mathrm{T}$ plots of the samples indicated near single domain behavior.

\section{Conclusion}

The samples $\mathrm{Mn}_{\mathrm{x}} \mathrm{Zn}_{1-\mathrm{x}} \mathrm{Fe}_{2} \mathrm{O}_{4}$ with $\mathrm{x}=0.4, \quad 0.5$ and 0.6 prepared using mechano-chemical method with photocatalytic auto combustion- self decomposition, were found to have spinel structure. This was confirmed using XRD and IR spectroscopy. The chemical composition was confirmed with AAS.

The particle sizes were estimated using Scherer formula and were found to be in nano range. Nano-materials produced by this method show high values of saturation magnetization. Tc increases with Mn content and was found to be higher than for the bulk material.

The simple mechano chemical method using metallic oxides, as starting material, adopting photo catalytic auto combustion- self decomposition for the synthesis of the final material was found to produce high performance nanoparticles of $\mathrm{Mn}-\mathrm{Zn}$ mixed ferrite material.

\section{References}

[1] C. Kittel, "Introduction to Solid State Physics" 7th ed., John Wiley and Sons Inc., 1996.

[2] M. Lin, D. Zhang, J. Huang, J. Zhang, W. Xiao, H. Yu, L. Zhang, J. Ye, "The anti-hepatoma effect of nanosized $\mathrm{Mn}-\mathrm{Zn}$ ferrite magnetic fluid hyperthermia associated with radiation in vitro and in vivo", Nanotechnology 24(2013)255101-255109.

[3] M. L. Martins, M. J. Saeki, M. T. F. Telling, J. P. R. L. L. Parra, S. Landsgesell, R. I. Smith, H. N. Bordallo, "Development and characterization of a new bionanocomposite (bio-NCP) for diagnosis and treatment of breast cancer", J. Alloys Compd., 584(2014) 514519.

[4] H. Saotome, Y. Sakaki, "Iron loss analysis of Mn-Zn ferrite cores", IEEE Trans. Magn. 33 (1997) 728-734.

[5] J. Xie, C. Yan, Y. Zhang, N. Gu, "Shape evolution of multi branched $\mathrm{Mn}-\mathrm{Zn}$ ferrite nano structures with high performance: a transformation of nano crystals into nanoclusters", Chem. Mater. 25(2013)3702-3709.

[6] S. Tao, A. Borrasso, B. Liu, V. Dravid, J. Am. Ceram. Soc. 94(5) (2011) 1490-1495.

[7] M. Sivakumar, A. Towata, K. Yasui, T. Tuziuti, T. Kozuka, Y. Iida, M. M. Maiorov, E. Blums, D. 
Bhattacharya, N. Sivakumar, M. Ashok, Ultrason. Sonochem.19 (3) (2012) 652-658.

[8] J. Moulin, Y. Champion, J.M. Greneche, F. Mazaleyrat, Magnetic properties of $\mathrm{Mn} \mathrm{Zn}$ ferrite with ultra-fine grain structure, J. Magn. Magn. Mater.254 (2003) 538540 .

[9] A. Angermanna, J. Topfera, K. L. Silva, K. D. Becker, "Nanocrystalline Mn-Zn ferrites from mixed oxalates: synthesis, stability and magnetic properties", J. Alloys Compd. 508 (2010) 433-439.

[10] R. Arulmurugan, G. Vaidyanathan, S. Sendhilnathan, B. Jeyadevan, J. Magn. Magn. Mater. 298 (2006) 83.

[11]C. Venkataraju, G. Sathishkumar, K. Sivakumar, J. Magn. Magn. Mater. 322 (2010) 230-233.

[12] M. Rozman, M. Drofenik, J. Am. Ceram. Soc. 78 (9) (1995) 2449.

[13] C. Upadhyay, H. C. Vermaa, C. Ratha, K. K. Sahub, S. Anande, R. P. Dasc, N. C. Mishra, "Mossbauer studies of nanosize $\mathrm{Mn}_{1}{ }_{\mathrm{x}} \mathrm{Zn}_{\mathrm{x}} \mathrm{Fe}_{2} \mathrm{O}_{4}$," J. Alloys Compd. 326 (2001) 94-97

[14] J. Azadmanjiri, "Preparation of $\mathrm{Mn}-\mathrm{Zn}$ ferrite nanoparticles from chemical sol-gel combustion method and the magnetic properties after sintering", J. Non-Cryst. Sol. 353 (2007) 4170-4173.

[15] K. I. Liu, Y. C. Hsueh, C. Y. Su, T. P. Perng, Int. J. Hydrogen Energy 38 (19) (2013) 7750-7755.

[16]I. Ali, M. U. Islam, M. S. Awan, M. Ahmad, M. N. Ashiq., J. Alloys Compd. 550 (2013) 564-572..

[17] M.R. Syue, F. J. Wei, C. S. Chou, C. M. Fu, J. Appl. Phys.109(7)(2011) 07A324.

[18]R. A. Waldron Phy.Rev.99 (1955) 1727

[19] V. C. Farmer, "The Infrared Spectra of Minerals" ed. V. C. Farmer, Mineralogical Society, London, (1974) 18.

[20] R. Iyer, R. Desai, R. V. Upadhyay, Bull. Mater. Sci., 32 2, ( 2009) pp. 141-147.

[21] R. A. Dunlap, A. Alghamdi, J.W. O'Brien, S. J. Penney J. Alloys Comp.365 (2004) 84-88.

[22] E. V. Gopalan, I. A. Al-Omari, K. A. Malini, P. A. Joy, D. S. Kumar, Y. Yoshida, M. R. Anantharaman, J. Magn. Magn. Mater., 321, (2009)1092.

[23] Y. Xuan, Q. Li, G. Yang Journal of Magn. Magn. Mater. 312 (2007) 464-469.

[24] L. Nalbandian , A. Delimitis , V. T. Zaspalis , E.A. Deliyanni, D. N. Bakoyannakis, E. N. Peleka, Micro. Meso. Mater. 114 (2008) 465-473.

[25] P. Papazoglou, F. Eleftheriou, V. T. Zaspalis, J. Magn. Magn. Mater. 296 (2006) 25

[26] S. Dasgupta, J. Das, J. Eckert, I. Manna, J. Magn. Magn. Mater. 306 (2006) 9.

[27] M. M. Hessien, M. M. Rashad, K. El-Barawy, I. A. Ibrahim. J Magne. Magn. Mater. 320 (2008) 1615-1621

[28] C. Rath, S. Anand, R. P. Das , J. App. Phys. 91(2002)2211.

[29] J. P. Chen, C. M. Sorenson, K. J. Klabunde, G. G. Hadjipanayis, E. Delvin, A. Kostidas, Phys. Rev. B54 (1996) 9288. 